\title{
THE IMPACT OF COVID-19 ON LOGISTICS AND THE ASSOCIATED DISRUPTIONS
}

\author{
Mohit Mohanan $\mathbf{T}^{1}$, Dr.Vandana Sonwaney ${ }^{2}$ \\ ${ }^{1}$ Student, Symbiosis Institute of Operations Management, Nashik 422008, India \\ 2 Director, email id - director@siom.in, Symbiosis Institute of Operations Management, Nashik 422008, India.
}

\begin{abstract}
This research study was conducted with the purpose of understanding the impact of COVID-19 on the logistics segment and the associated disruptions in the food supply chain. In the current times, the entire world is challenged by a disease called coronavirus or popularly known as Covid-19. In December 2019, Wuhan in China reported the first case ever. COVID-19 has heavily affected the supply chain networks, logistics in particular. Markets and firms are connected by Logistics companies through the provision of different services, including multimodal transportation, freight forwarding, warehouse management, and inventory management. A diverse pool of logistics players across the world have been impacted owing to the current state of the pandemic. This paper analyzes the disruptions in the movement and delivery of essential food items and how resilient a supply chain should be during such periods of crisis. An experiment was carried out to understand the factors affecting the food essentials delivery to the local kirana stores. For this, a survey of 200 respondents (kirana shop owners) was conducted with the help of a 14-item questionnaire. Factor analysis was the tool used to analyze the results and the software used was SPSS. The outcome of the analysis showed that 5 factors were extracted which tried to explain the 14 variables used in the survey which were afflicted due to the coronavirus pandemic.
\end{abstract}

\section{Article Received: 10 August 2020, Revised: 25 October 2020, Accepted: 18 November 2020}

\section{Introduction}

E Disorders in the supply chain have occurred in the past as well due to man-made disasters or natural calamities. Instances of the magnitude of the Japan Tsunami in 2011, the earthquake in Gujarat (2001), Indian ocean earthquake (2004), earthquake in Haiti in 2010. A new global pandemic has disrupted the supply chain ecosystem heavily. It has not only impacted human lives but has also caused severe slowdown in many economic related activities viz. manufacturing, logistics, distribution and supply chain among other functions. It has also hit various sectors like tourism and hospitality, automobile industry, aviation sector, oil and gas industry, telecom and food industry. [5]

The World Health Organization (WHO), in January 2020, declared the outbreak of a new coronavirus disease, COVID-19 as a Public Health Emergency of International Concern.[10] As stated by WHO, the entire world being exposed to this deadly virus is very high. In March 2020, an appraisal was made by the WHO that COVID-19 can be portrayed as a pandemic. [1]

Till September 2020, the number of COVID-19 cases globally is $32,730,945$ and the fatalities account to $9,91,224$. These numbers are rising rapidly as there are close to 7 million active cases. With such disturbing numbers, the general mindset amongst the common public is of anxiety and fear. In India, the numbers are increasing quickly too with more than 5.5 million cases in total. Out of these cases, there have been 94,503 deaths and the number of daily cases is at an alltime high of more than 76,000 cases. [11]

All fields are associated in a complicated system of supply chain, logistics in particular, yet barely any exercises manifested throughout the coronavirus pandemic. Throughout the world, financial exercises arrived at the absolute bottom and all the international financial institutions have anticipated an economic recession and financial crunch globally. [7]

There has been a heavy impact on supply chain, logistics operations due to pandemic. The logistics and the distribution network form an important arm for smooth conduct of the supply chain operations. Basic and essential food materials had to be delivered to the masses. This called for a resilient and a robust logistics network. [9]

The study is divided into 9 sections. Literature review of the study is discussed in section 2. The effect of COVID-19 on the economy has been mentioned in Section 3. Sections 4 talks about the methodology used in understanding and 
presenting the study. Section 5 and 6 details the data gathering and the associated analysis of the study. Finally, the last 3 sections cover the conclusion of the study, the limitations and the scope for future study.

\section{LITERATURE REVIEW}

There have been numerous studies and researches conducted to study the impact of this pandemic on supply chain and logistics and distribution network as a whole.

The movement of goods along supply chains have been disturbed by various bottlenecks in transport and logistics. In a broader sense, three primary methods of transport are used to transport agricultural and food products viz. bulk (ships); containers (by boat, rail or truck) and other means of road transport; and air cargo. Distinct modes of transport are used for different types of products: oilseeds and cereals, for instance, are ordinarily transported in large quantities; dairy eatables and meat are frequently transported in temperaturecontrolled trucks and containers; and perishable items are carried via air in the "bellies" of passenger planes. No significant disturbances have been seen in bulk shipments, and costs for bulk goods are in reality close to lows in multiple years. However, there has been a severe impact on air freight. The capacity of air cargo worldwide in the seven-day stretch of 10 to 16 May reduced by 26 percent from the same period a year ago, Europe and Latin America witnessed the biggest decrease in capacity on routes (with declines of above $80 \%$ ).[3]

In countries like China, various studies pertaining to the global hunger issues arising out of the pandemic have been studied. One such study (Sarkar et al., 2020) focused on the issues related to food security wherein the determinants of the food security were studied and analyzed with the help of factor analysis. [8]

In India, due to several restrictions, the transportation system had taken a hit. The 2 nd or 3rd day of the lockdown saw the most severe effect of COVID-19 when operation of trucks reduced by more than $90 \%$. Only the essential goods which did not come under the purview of limitations imposed due to the lockdown contributed to the transportation movement. [4]

During such severe cases when other means of food supply becomes a challenge, the local kirana shop was a real life-saver for millions of people.
These shops have played a significant part in giving help to individuals in the consequence of the nation-wise lockdown. With the increase in COVID-19 cases and the economy proceeding towards a decline, setting up of remedial measures in order to ensure that there are no distinctions is essential. Also, essential food items must reach every household to avoid nation-wide hunger and deprivation of food. The Azim Premji University conducted a survey on COVID-19. The findings state that procurement of food grains was possible for 69 per cent of urban and 89 per cent of rural population from a government ration shop whereas the Jan Dhan transfer was made available to only one-third of the households. [12]

Data pertaining to various government websites and editorials were referred to analyze the pattern of the logistics network. COVID-19 pandemic has seriously impacted a wide range of food supply chains, for instance, fresh fruits and vegetables, perishable products, bakery products other than food grains. Due to imposition of lockdown, logistics activities have been hampered which ultimately resulted in scarcity of essential food items with the public. [4]

The local kirana shop system was too impacted by the restrictions in place. Access to various places was not possible. Also, due to several migrants returning back to their hometowns, labour force to ensure the transportation related to movement as well as loading and unloading was unavailable. The activity of $10 \%$ trucks out of 14 lakh and similar movement for light commercial vehicles encapsulate the effect of lockdown. In addition to less vehicular availability and reduced labour force, the challenge was the inaccessibility to reach high-risk areas or the containment zones. This study captures the impact of coronavirus on the supply of essential food items to the general public. [4]

It is essential to understand which category of edible food products was heavily impacted owing to the pandemic. There can be various factors which play a role in both production and distribution of the food items. By reviewing and studying all these works, it can be ascertained that pandemic's impact on supply chain and especially logistics can be studied further. Researchers and experts in the past have studied supply chain disruptions owing to various pandemics and epidemics. However, there has not been enough study on COVID-19 as a pandemic. With this 
research paper, I have focused on understanding the real-world and the ground scenarios related to logistics management during these uncertain times. I have used Factor analysis as the tool in this study to ascertain the factors which were affected in the wake of the pandemic.

\section{EFFECT OF COVID-19 ON ECONOMY:}

The coronavirus disease has hit not only human lives but has also grappled economies of the world, especially in developing countries. The figures related to mortality and infections as well as the recovery rate have been fluctuating continuously. As per data from Our World in Data, the cases in India are increasing at a fast pace, around 60,000 cases daily nationwide. By August 2020 end, the total number of cases in India crossed 3 million.[13] The quantity of affirmed cases is lower than the number of actual cases; the primary reason for that is limited testing. Social distancing guidelines have been laid out by WHO and individual countries are advised to follow them to avoid the spread of the virus.

Countries globally have taken a step further and have imposed time-based lockdowns. However, such lockdowns although devised and implemented to restrict the containment of the disease, they will grapple the economy and will result in a complete undesirable situation in terms of public sentiment as well. In India, around 90\% of the population comprises of labour workforce most of which are dependent on daily wages for their existence.[15] This corona virus-caused lockdown has brought misery to their lives, forcing them to return to their hometowns due to industries and mills etc being closed. Worldwide, too, the lockdown has resulted in huge job losses and. As per an underlying assessment by the International Labour Organization (ILO) COVID19 could severely impact close to 25 million job positions worldwide, and the number may rise to 40 Million. [14] 30-40\% of Indian employees are on the brink of losing their jobs after lockdown as opined by $52 \%$ of CEOs in a report delivered by the CII employment in India post-lockdown. [2]. The IMF had attested that the pandemic will have a more devastating effect on the global economy than 1929's Great Depression.[6] These disturbing statistics tell us that the fight is both against the virus in terms of saving public lives as well as to stabilize and prevent derailing of the economy.

\section{METHODOLOGY:}

The research was conducted with respect to India on the logistics network prevalent in the country and also how the pandemic has hit the logistics industry as a whole. The research revolved around the transportation of food grains and other essential items to all over the country through the local kirana stores.

The fundamental tool of analysis used in the research is Factor Analysis. The steps consisted of:

a) Data collection from around 200 local kirana shop owners. A questionnaire was floated directly to 15 local shop owners while the rest of the data was collected through online forms.

b) Incorporating the collected data in the SPSS tool for Factor Analysis.

c) Analyzing, validating the outcome and deriving conclusions.

Factor analysis is of two types: a) Principal component analysis b) Common factor analysis

In this research case, we have used Principal component analysis. A one-of-a-kind solution can be achieved through this method in the sense that the outcomes can be used to reproduce the original data. The variables' total variance is taken into consideration.

\section{DATA GATHERING:}

In order to analyze COVID-19's impact on the food items, it was imperative to gather real-time data from the local departmental or the kirana shops. A survey was conducted by floating a 14item questionnaire to the local shop owners to understand the effect on various products. A 5point Likert scale was used to design the answers for the survey. The sample size was of 200 respondents. The design of the questionnaire was based on the usual problems that would have been faced by the kirana shops. This design was done on the basis of some relevant study. The survey was a questionnaire which comprised of the following broad areas and had 14 questions overall

1. Frequency of order delivery

2. Quantity of goods

3. Unavailability of goods

4. Pricing patterns

5. Alternative brands of goods 
This survey consisting of these questions was then conducted on 200 local kirana shop owners (15 interviews were conducted in person while the rest of the data was captured via an online form).

For the purpose of capturing possible responses through survey, a code sheet was produced for the questionnaire. The objective of this code sheet is to give numerical value to text questions to aid in further analysis.

\section{SURVEY FINDINGS AND OBSERVATION:}

Based on the survey conducted on 200 local kirana shop owners, these are the following results. Since each of the respondent had given answers to all the questions, there were no cases of missing data. However, a missing check was done on SPSS which verified the same. Data was used as-is. As mentioned earlier, SPSS was used to analyze the dataset.

The total number of questions in the questionnaire was 14 and Chronbach's alpha coefficient was found to be 0.876 meaning the research tool is adequate and sufficient enough to be considered in the data collection process. The statistical technique used within the factor analysis was exploratory factor analysis. The variable matrix is the initial dataset for the factor analysis having the variables and the associated scores. The KaiserMeyer-Olkin measure of sampling adequacy and the Bartlett's test of sphericity are the two tests that can be utilized to decide the matrix's factorability. The dataset for the factor analysis should contain significant information which can be ascertained by the Bartlett's Test of sphericity. This test found the data to be significant (since $\mathrm{p}<0.05)$. The Bartlett test is important from the point of view of factor analysis. Bartlett's test states that in the null hypothesis, the variables are correlated with themselves as it were. In this case, the null hypothesis is rejected and this demonstrates that there is an existence of significant information in the correlation matrix and also minimum necessary conditions required for factor analysis. The KMO is the suitable test to ensure that the sample size is considerable enough to employ the factor analysis. A value of more than 0.6 indicates a considerable sample size. The value of $\mathrm{KMO}$ in this case was 0.686 which indicates that factor analysis can be applied. The Kaiser criteria helps us in extracting 5 factors whose Eigen values higher than one.

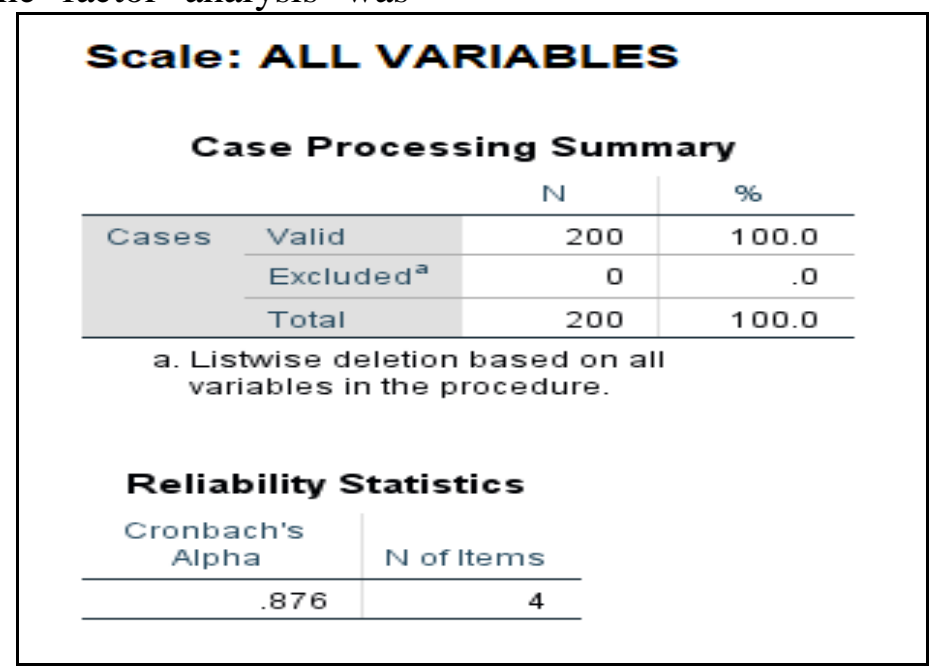

Figure 2: Reliability Test

\begin{tabular}{|c|c|c|}
\hline \multicolumn{3}{|c|}{ KMO and Bartlett's Test } \\
\hline \multicolumn{2}{|c|}{ Kaiser-Meyer-Olkin Measure of Sampling Adequacy. } & .686 \\
\hline \multirow{3}{*}{$\begin{array}{l}\text { Bartlett's Test of } \\
\text { Sphericity }\end{array}$} & Approx. Chi-Square & 1111.626 \\
\hline & df & 91 \\
\hline & Sig. & .000 \\
\hline
\end{tabular}

Figure 3: KMO and Bartlett's Test 
The total variance explained by the 5 factors having an Eigen value of above 1 is $76.07 \%$ which is a remarkable figure. These factors explain all the 14 variables which affect the local kirana shop businesses due to the COVID-19 pandemic. These 5 factors can be verified by the scree plot as well.

\begin{tabular}{|c|c|c|c|c|c|c|c|c|c|}
\hline \multirow[b]{3}{*}{ Component } & \multicolumn{9}{|c|}{ Total Variance Explained } \\
\hline & \multicolumn{3}{|c|}{ Initial Eigenvalues } & \multicolumn{3}{|c|}{ Extraction Sums of Squared Loadings } & \multicolumn{3}{|c|}{ Rotation Sums of Squared Loadings } \\
\hline & Total & $\%$ of Variance & Cumulative $\%$ & Total & $\%$ of Variance & Cumulative $\%$ & Total & $\%$ of Variance & Cumulative $\%$ \\
\hline 1 & 3.050 & 21.785 & 21.785 & 3.050 & 21.785 & 21.785 & 2.936 & 20.974 & 20.974 \\
\hline 2 & 2.429 & 17.349 & 39.134 & 2.429 & 17.349 & 39.134 & 2.308 & 16.489 & 37.463 \\
\hline 3 & 2.142 & 15.302 & 54.437 & 2.142 & 15.302 & 54.437 & 2.151 & 15.367 & 52.830 \\
\hline 4 & 1.656 & 11.832 & 66.268 & 1.656 & 11.832 & 66.268 & 1.668 & 11.917 & 64.747 \\
\hline 5 & 1.372 & 9.802 & 76.070 & 1.372 & 9.802 & 76.070 & 1.585 & 11.323 & 76.070 \\
\hline 6 & .568 & 4.060 & 80.130 & & & & & & \\
\hline 7 & .529 & 3.782 & 83.912 & & & & & & \\
\hline 8 & .429 & 3.066 & 86.978 & & & & & & \\
\hline 9 & .396 & 2.830 & 89.808 & & & & & & \\
\hline 10 & .338 & 2.414 & 92.222 & & & & & & \\
\hline 11 & .329 & 2.351 & 94.573 & & & & & & \\
\hline 12 & .304 & 2.169 & 96.742 & & & & & & \\
\hline 13 & .255 & 1.819 & 98.561 & & & & & & \\
\hline 14 & .201 & 1.439 & 100.000 & & & & & & \\
\hline
\end{tabular}

Figure 4: Total explained variance

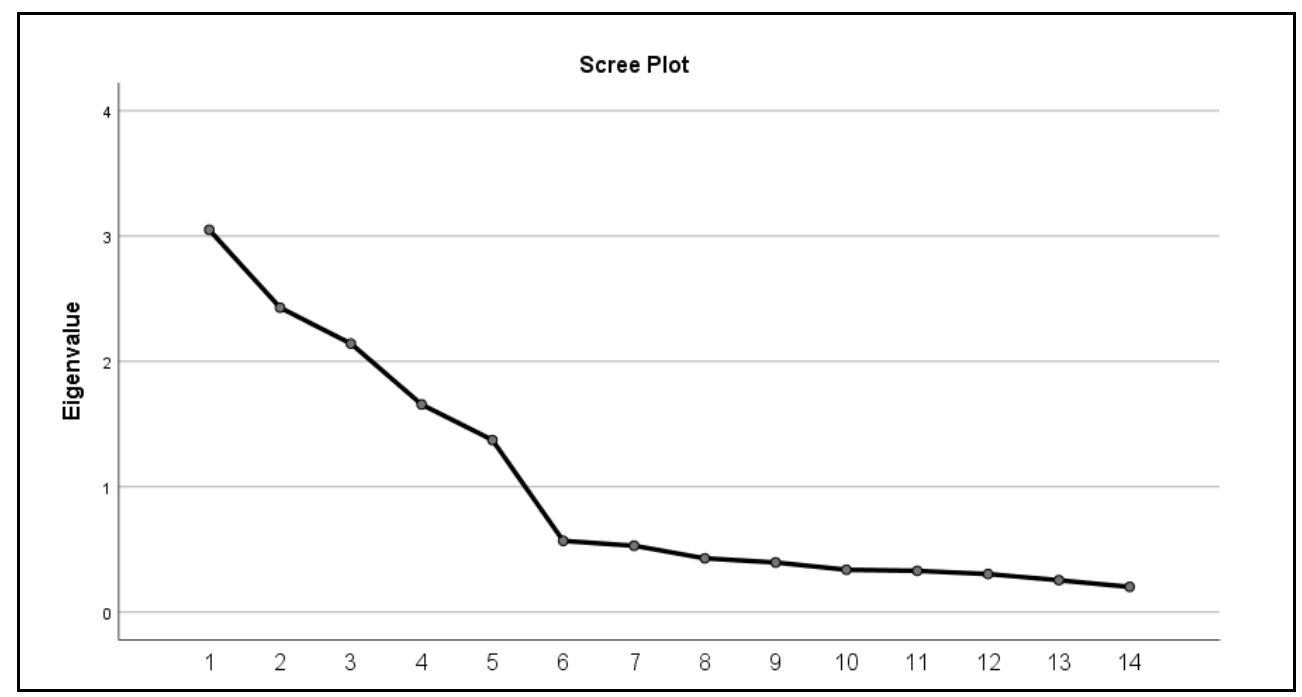

Figure 5: Scree Plot

The image shows the rotated factor matrix. The rotation method used is Varimax with Kaiser normalization. Factor 1 comprised of 4 variables viz. variables V8, V7, V9 and V6 whose factor loadings range from 0.792 to 0.884 . Factor 2 consisted of 3 variables whose factor loadings range from 0.835 to 0.913 . The variables within
Factor 2 are V10, V12 and V11. Factor 3 also consisted of 3 variables i.e. V3, V4 and V5 whose factor loadings range from 0.811 to 0.867 whereas the variables in Factor 4 are V14 and V13 whose factor loadings are 0.910 and 0.900 respectively. The last factor i.e. Factor 5 had two variables i.e. V2 and V1. Their factor loadings are 0.886 and 0.860 . 


\begin{tabular}{|c|c|c|c|c|c|}
\hline \multicolumn{6}{|c|}{ Rotated Component Matrix ${ }^{a}$} \\
\hline & \multicolumn{5}{|c|}{ Component } \\
\hline & 1 & 2 & 3 & 4 & 5 \\
\hline VAR0008 & .884 & & & & \\
\hline VAR0007 & .874 & & & & \\
\hline VAR0009 & .857 & & & & \\
\hline VAR0006 & .792 & & & & \\
\hline VAR0010 & & .913 & & & \\
\hline VAR0012 & & .865 & & & \\
\hline VAR0011 & & .835 & & & \\
\hline VAR0003 & & & .867 & & \\
\hline VAR0004 & & & .831 & & \\
\hline VAR0005 & & & .811 & & \\
\hline VAR0014 & & & & .910 & \\
\hline VAR0013 & & & & .900 & \\
\hline VAR0002 & & & & & .886 \\
\hline VAR0001 & & & & & .860 \\
\hline \multicolumn{6}{|c|}{$\begin{array}{l}\text { Extraction Method: Principal Component Analysis. } \\
\text { Rotation Method: Varimax with Kaiser Normalization. }\end{array}$} \\
\hline a. Rota & onverge & 5 iteratic & & & \\
\hline
\end{tabular}

Figure 6: Rotated component matrix (Varimax)

Factor analysis was used to construct 5 new factors and were assigned as the factors affecting the local kirana business during the pandemic. The first factor can be named as 'Unavailability of goods and the associated consumer sentiment'. It explains $21.87 \%$ of the variance. The second factor can be named as 'Ordering pattern and behavior' which explains $17.349 \%$ of the variance. The third factor can be named as 'Quantity, and it explains $15.302 \%$ of the variance. The fourth extracted factor can be named as 'Pricing changes' and this factor explains $11.832 \%$ of the variance. The final factor can be named as 'Timeliness of order delivery' and this explains $9.802 \%$ of the variance. In all, the five factors combined explain $76.07 \%$ of the variance.

\section{CONCLUSION:}

The study mainly revolved around the supply of essential food items to the homes of the general public. Various product categories were considered as a part of this research. It can be understood that COVID-19 has caused major disruptions in the logistic sphere and the research paper has exemplified these effects. With the help of exploratory factor analysis, 5 distinct factors viz. Consumer sentiment, ordering pattern and behavior, Quantity, Pricing changes and
Timeliness of order delivery were understood as the main attributes on which the local kirana shop owners were affected upon. The use of a 14-item questionnaire based on a Likert scale helped in conducting this analysis. Around 200 respondents were a part of the survey conducted. The paper helps us in concluding that the logistics of essential food delivery items was hit due to the lockdown and other limitations imposed by the coronavirus.

\section{LIMITATIONS:}

The scope of the study was restricted to only kirana shops in the areas of Kalyan, Ambernath and Dombivli. In case of varying levels of problems associated with logistics in other areas or in a bigger region, the study might have slightly differing outcomes. Also, only local kirana shops were taken into consideration which are not the only sources of food distribution.

\section{FUTURE SCOPE:}

In addition to essential food items, other nonessential food items can also be considered as a part of the future analysis and study. Also, supermarkets and Public Distribution System (PDS) can also be studied and researched upon.

The EFA results can be used to study and move ahead with confirmatory factor analysis (CFA). A 
CFA test can be applied with a new sample dataset to the measure's dimensionality or construct validity.

\section{REFERENCES:}

[1] Chamola, V., Hassija, V., Gupta, V., \& Guizani, M. (2020). A Comprehensive Review of the COVID-19 Pandemic and the Role of IoT, Drones, AI, Blockchain, and $5 \mathrm{G}$ in Managing its Impact. IEEE Access, 8(April), 90225-90265. https://doi.org/10.1109/ACCESS.2020.2992341

[2] CII. (n.d.). Retrieved February 10, 2021, from https://www.cii.in/PublicationDetail.aspx?

[3] Comparing crises: Great Lockdown versus Great Recession. (2020). In Comparing crises: Great Lockdown versus Great Recession. https://doi.org/10.4060/ca8833en

[4] Covid-19 lockdown: Transporting goods still a challenge despite govt orders. (n.d.). Retrieved February 10, 2021, from https://www.livemint.com/news/india/covid-19lockdown-transporting-goods-still-a-challengedespite-govt-orders-11585909166425.html

[5] Dolgui, A., Ivanov, D., \& Sokolov, B. (2020). Reconfigurable supply chain: the Xnetwork. International Journal of Production Research, 58(13), 4138-4163. https://doi.org/10.1080/00207543.2020.1774679

[6] Gopinath, G. (2020). The Great Lockdown: Worst Economic Downturn Since the Great Depression - IMF Blog. Global Economy, 1-10. https://blogs.imf.org/2020/04/14/the-greatlockdown-worst-economic-downturn-since-the-greatdepression/

[7] Lucchese, M., \& Pianta, M. (2020). The Coming Coronavirus Crisis: What Can We Learn? Intereconomics, 55(2), 98-104. https://doi.org/10.1007/s10272-020-0878-0

[8] Sarkar, A. (n.d.). Determinant of Food Security Within the COVID-19 Epidemic Circumstances- A Special Case of Chinese Agriculture Food Production and Distribution Industries. 1-24.

[9] Singh, S., Kumar, R., Panchal, R., \& Tiwari, M. K. (2020). Impact of COVID-19 on logistics systems and disruptions in food supply chain. International Journal of Production Research, 0(0), 1-16. https://doi.org/10.1080/00207543.2020.1792000
[10] World Health Organization. (2019). A world at risk. In Global Preparedness Monitoring Board (Issue September). https://apps.who.int/gpmb/assets/annual_report/GPM B_annualreport_2019.pdf

[11] WHO. (2020). Coronavirus Disease (COVID-19) Situation Reports Updates 27 September 2020. World Health Organization Technical Report Series, September, 1-23. https://www.who.int/docs/defaultsource/coronaviruse/situation-reports/20200928weekly-epi-update.pdf?sfvrsn=9e354665_6

[12] COVID-19 lockdown has devastated livelihoods: Azim Premji Uni survey | The News Minute. (n.d.). Retrieved February 15, 2021, from https://www.thenewsminute.com/article/covid-19lockdown-has-devastated-livelihoods-azim-premjiuni-survey-124499

[13] India: Coronavirus Pandemic Country Profile - Our World in Data. (n.d.). Retrieved February 15, 2021, from https://ourworldindata.org/coronavirus/country/india? country= IND

[14] Monitor, I. L. O. (2020). . Current situation: Why are labour markets important? March, 1-15. https://gisanddata.maps.arcgis.com/apps/opsdashboar $\mathrm{d} /$ index.html

[15] Labour Bureau, M. of L. \& E. (2015). Report on Employment in Informal Sector and Conditions of Informal Employment. 1126. https://labour.gov.in/sites/default/files/Report vol 4 final.pdf 